\title{
POLÍTICAS PÚBLICAS DE ESPORTE NO INTERIOR DA BAHIA: OS MUNICÍPIOS EM FOCO
}

\author{
Nadson Santana Reis \\ Universidade de Brasília, Brasília, Distrito Federal, Brasil. \\ Fernando Mascarenhas \\ Universidade de Brasília, Brasília, Distrito Federal, Brasil.
}

O livro Políticas públicas de esporte no interior da Bahia, organizado pelos professores Osni Silva, Michael Ramos, Temístocles Silva e Gildison Souza, ${ }^{1}$ compõe uma série de dois volumes que reúnem pesquisas diversas sobre as políticas públicas de esporte e lazer em algumas cidades do interior da Bahia. A obra em destaque é resultado da contribuição de pesquisadores alocados em quatro grupos de pesquisas ${ }^{2}$ distribuídos em três universidades estaduais (Universidade do Estado da Bahia - UNEB, Universidade Estadual de Feira de Santana - UEFS e Universidade Estadual do Sudoeste da Bahia - UESB).

A obra reúne textos que problematizam a dinâmica das políticas públicas de esporte em seis municípios baianos (Serrolândia, Capim Grosso, Quixabeira, Mirangaba, Jacobina mesorregião Centro Norte Baiano - e Jequié - mesorregião Centro Sul Baiano). Os textos situam o esporte como um direito social de responsabilidade do Estado, que, por isso, demanda políticas públicas comprometidas com a equidade e a justiça social.

O primeiro texto do livro, "Neoliberalismo e suas implicações nas políticas públicas de esporte no interior da Bahia", de Michael Ramos, Osni Silva e Gildison Souza, discute, em linhas gerais, os desdobramentos do neoliberalismo para as políticas públicas de esporte, situando a agenda neoliberal, o Estado mínimo, o ataque aos direitos fundamentais na América Latina e, sobretudo, o papel das políticas públicas de esporte nesse contexto aspecto tratado à luz da desresponsabilização do Estado, do avanço do terceiro setor, do foco no alto rendimento, da promoção da paz e da diminuição das desigualdades sociais, bem como da redução dos "[...] quadros de injustiça, exclusão e vulnerabilidade social [...]" (p. 36), os quais, segundo os autores, são forjados pelas próprias políticas neoliberais.

O segundo capítulo, "Análise das políticas públicas de esporte no município de Serrolândia-BA", escrito por Dyego Costa e Osni Silva, apresenta as políticas públicas de esporte desenvolvidas entre 2009 e 2012 no referido município. Nesse texto, os autores avaliam as ações implementadas pelo executivo municipal, as estruturas esportivas e o planejamento das ações ligadas ao esporte. Apesar de alguns descompassos entre a discussão apresentada sobre o direito ao esporte e a literatura sobre a questão (LINHALES, 1996; MANHÃES, 2002; VERONEZ, 2005; BUENO, 2008, por exemplo), bem como da ausência de dados empíricos e/ou referências para algumas (poucas) passagens, o texto conclui ressaltando a ausência de equipamentos e bens públicos que atendam à população no tocante ao acesso às atividades esportivas, além de situações de completo abandono dos

\footnotetext{
${ }^{1}$ SILVA et al. (Org.). Políticas de esporte no interior da Bahia. Rio de Janeiro: Eulim, 2017.

${ }^{2}$ Grupo de Estudos, Pesquisa e Extensão em Educação Especial e Educação Física Adaptada (GEPEFA), Grupo de Estudos, Pesquisa e Extensão em Educação Física, Esporte e Lazer (GEFEL), Grupo de Estudo e Pesquisa em Educação Física e Esporte e Lazer (LEPEL-UNEB) e Centro de Estudos em Gestão do Esporte e Lazer (CEGEL).
} 
equipamentos públicos existentes, falta de manutenção, de gestão compartilhada, segurança e, até mesmo, de encaminhamento em ações previstas para o setor. Para os autores, esse quadro é alimentado por uma política de eventos - bastante presente no setor - que se desenvolve no "fosso" criado pela ausência de planejamento e pelos escassos recursos que marcam a área. Tais problemas, para os pesquisadores, poderiam ser minimizados caso houvesse espaços de controle social como, por exemplo, um conselho municipal de esporte.

O terceiro texto, "Investimento público em esporte na cidade de Capim Grosso 20062014: uma análise no portal da transparência municipal", de Gildison Souza e Osni Silva, situa, por meio do caso do município de Capim Grosso, a ausência de estudos sobre investimentos públicos municipais no esporte. O trabalho inicia discutindo a questão das políticas públicas de esporte, no Brasil, numa perspectiva histórica para, só então, abordar o caso do município em questão. Ao fazê-lo, os autores, de modo descritivo/narrativo, identificam um aumento no investimento público (federal e municipal) nas ações ligadas ao esporte. Tais investimentos incidem, segundo os pesquisadores, sobre pessoal e infraestrutura - o que, apesar de tudo, não responde satisfatoriamente às demandas do município.

O quarto texto, "Políticas públicas de esporte no município de Quixabeira/BA entre os anos de 1989 a 2016", de Denise Mendes e Michael Ramos, apresenta, de modo panorâmico, as ações em torno do esporte no referido município. O artigo, apesar da pouca interlocução com a literatura especializada no assunto, assinala que, em Quixabeira, o esporte não tem recebido a devida importância, já que fica restrito a campeonatos/eventos relacionados aos esportes de quadra/coletivos. Essas questões limitam as ações ao campo de construção e/ou reformas de campos society, quadras e estádios.

O quinto artigo, "Análise da acessibilidade nos equipamentos públicos municipais para a prática esportiva na cidade de Mirangaba, Bahia", de Assis Santos Luiz e Osni Silva, reflete sobre a acessibilidade para a prática esportiva. Nele, os autores pontuam sobre a legislação que trata da acessibilidade em equipamentos públicos, tomando essa questão com fundamental para o pleno exercício da cidadania de pessoas com deficiência. A análise dos equipamentos públicos de Mirangaba leva os autores a verificarem um conjunto de inadequações com as normas técnicas para a garantia da acessibilidade, o que dificulta o acesso a tais espaços e, consequentemente, à prática esportiva - fato que implica a completa ausência de atividades esportivas adaptadas no município.

O antepenúltimo texto, "Ações dos poderes legislativo e executivo relacionadas as políticas públicas de esporte no município de Jacobina - 2003 a 2016", de Nilton Santos e Michael Ramos, busca apresentar as ações dos poderes executivo e legislativo no que tange às políticas de esporte no município em questão. Nesse sentido, os autores apresentam e analisam o arcabouço legal produzido pelo executivo e pelo legislativo municipais entre 2003 e 2016. Tal percurso permitiu identificar ações como a construção e a nomeação de equipamentos esportivos públicos, a implementação de projetos e programas esportivos, a dotação orçamentária para o setor, a concessão de título de utilidade pública, além da construção de estrutura organizacional, administrativa e política para o esporte.

O penúltimo texto, "Políticas públicas na cidade de Saúde - Bahia: uma análise documental", de Maritel Silva e Jessica Terra Nova, situa as políticas públicas como ações do Estado que visam à garantia das necessidades da população, considerando, nesse processo, referenciais da vulnerabilidade social, das situações de risco social e da propagandeada convivência socioeducativa. Nesse ínterim, os autores situam o esporte como um direito social que está presente na Lei Orgânica do município, vinculado, inclusive, a outras áreas. Para os pesquisadores, a normatização legal de saúde do município apresenta pontos em comum com outros municípios vizinhos.

O último texto, "A política esportiva do município de Jequié/BA e seus reflexos no desenvolvimento urbano", de Temistocles Silva, Laumar Souza e Felipe Marta, aloca o 
esporte no âmbito das atividades econômicas globais, inserindo-o na lógica comercial, na esfera do planejamento urbano, bem como no contexto dos megaeventos esportivos. Para o contexto municipal, os autores localizam a Secretaria de Esporte e Lazer como um marco importante para a gestão das políticas/ações do setor, já que é balizada pelos princípios da universalização do esporte e do lazer - associados ao desenvolvimento econômico e social. Nesse estudo, os autores pontuam avanços que vão desde a construção de equipamentos, realização de fóruns municipais de esporte e lazer, busca por parcerias, incremento da legislação esportiva, inserção do esporte e lazer como dimensões importantes para o planejamento urbano, até o aumento nos recursos que financiavam tais ações. Além disso, os estudiosos verificaram influências e/ou interferências do campo político no setor do esporte e do lazer. Por fim, assinalam a necessidade de construção/estruturação de um Sistema Municipal de Esporte e Lazer.

Em síntese, os textos apresentados no livro Políticas públicas de esporte no interior da Bahia apresentam/debatem questões importantes para as políticas de esporte no Brasil e tratam de aspectos fundamentais para o setor, como é o caso da participação dos municípios na implementação/execução de tais políticas. Responde, desse modo, à demanda por estudos que atendam às necessidades de reflexão, análise e avaliação sobre um conjunto de aspectos que atravessam as políticas públicas de esporte no país, em contextos que tem recebido pouca atenção - os municípios.

Embora o livro não contemple uma problematização adequada sobre a descentralização e o federalismo - elementos cruciais para as políticas públicas no Brasil -, fornece elementos fundamentais e pistas valiosas para se avaliar um conjunto de fatores complicadores, limitadores e/ou determinantes para a implantação, o desenvolvimento e a avaliações de tais ações.

Por fim, os textos respondem, ainda que inicialmente, à demanda por estudos que apontem os desdobramentos do federalismo e da descentralização nas "ações" de esporte ainda que não toquem diretamente nessas questões, assim como nas implicações do financiamento, da legislação e do formato/organização das políticas em questão. $O$ movimento/processo de análise, reflexão e problematização dessas questões, que pode ser caracterizado como bastante desafiador, estabelece, salvo algumas exceções, diálogos com a produção mais geral do campo, bem como com outras referências importantes - aspecto que nos levam a recomendar a leitura da obra, ainda que como um ponto de partida para novas pesquisas e novos estudos.

\section{Referências}

BUENO, L. Políticas públicas do esporte no Brasil: razões para o predomínio do alto rendimento. 2008. 296 f. Tese (Doutorado em Administração Pública e Governo) - Fundação Getúlio Vargas - GV, São Paulo, 2008.

LINHALES, M. A. A trajetória política do esporte no Brasil: interesses envolvidos, setores excluídos. 1996. 242 f. Dissertação (Mestrado em Ciência Política - Faculdade de Filosofia e Ciências Humanas - UFMG), Belo Horizonte, 1996.

MANHÃES, E. D. Políticas de esportes no Brasil. 2. ed. Rio de Janeiro: Graal, 2002.

SILVA et al. (Org.). Políticas de esporte no interior da Bahia. Rio de Janeiro: Eulim, 2017. 
VERONEZ, L. F. C. Quando o Estado joga a favor do privado: as políticas de esporte após a Constituição Federal de 1988. 2005. 270 f. Tese (Doutorado em Educação Física) Universidade Estadual de Campinas - Unicamp, Campinas, 2005.

Recebido em: 04/05/2018

Revisado em: 10/06/2018

Aprovado em: 18/07/2018

Endereço para correspondência:

nadsonsr@hotmail.com

Nadson Santana Reis

Universidade de Brasília,

Faculdade de Educação Física

Campus Universitário Darcy Ribeiro,

70910-900 - Brasília-DF, Brasil. 